ORIGINAL ARTICLE

\title{
Deficiency in trefoil factor 1 (TFF1) increases tumorigenicity of human breast cancer cells and mammary tumor development in TFF1-knockout mice
}

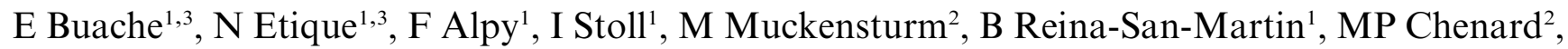 \\ C Tomasetto ${ }^{1}$ and $\mathrm{MC}$ Rio $^{1}$
}

${ }^{1}$ Institut de Génétique et de Biologie Moléculaire et Cellulaire (IGBMC), CNRS UMR 7104, INSERM U964, Université de Strasbourg, Illkirch, France and ${ }^{2}$ Service d'Anatomie Pathologique Générale, Centre Hospitalier Universitaire de Hautepierre, Strasbourg, France

\begin{abstract}
Although trefoil factor 1 (TFF1; previously named pS2) is abnormally expressed in about $50 \%$ of human breast tumors, its physiopathological role in this disease has been poorly studied. Moreover, controversial data have been reported. TFF1 function in the mammary gland therefore needs to be clarified. In this study, using retroviral vectors, we performed TFF1 gain- or loss-of-function experiments in four human mammary epithelial cell lines: normal immortalized TFF1-negative MCF10A, malignant TFF1negative MDA-MB-231 and malignant TFF1-positive MCF7 and ZR75.1. The expression of TFF1 stimulated the migration and invasion in the four cell lines. Forced TFF1 expression in MCF10A, MDA-MB-231 and MCF7 cells did not modify anchorage-dependent or -independent cell proliferation. By contrast, TFF1 knockdown in MCF7 enhanced soft-agar colony formation. This increased oncogenic potential of MCF7 cells in the absence of TFF1 was confirmed in vivo in nude mice. Moreover, chemically induced tumorigenesis in TFF1-deficient (TFF1-KO) mice led to higher tumor incidence in the mammary gland and larger tumor size compared with wild-type mice. Similarly, tumor development was increased in the TFF1-KO ovary and lung. Collectively, our results clearly show that TFF1 does not exhibit oncogenic properties, but rather reduces tumor development. This beneficial function of TFF1 is in agreement with many clinical studies reporting a better outcome for patients with TFF1-positive breast primary tumors.
\end{abstract}

Oncogene (2011) 30, 3261-3273; doi:10.1038/onc.2011.41; published online 28 February 2011

Keywords: TFF1/pS2; breast cancer; gain- and loss-offunction; human mammary cell lines; tumorigenicity; TFF1-KO mice
Correspondence: Dr MC Rio, Institut de Génétique et de Biologie Moléculaire et Cellulaire (IGBMC), CNRS UMR 7104, INSERM U964, Université de Strasbourg, Illkirch, France.

E-mail: rio@igbmc.fr

${ }^{3}$ Co-first authors.

Received 29 July 2010; revised 16 January 2011; accepted 20 January 2011; published online 28 February 2011

\section{Introduction}

Trefoil factor 1 (TFF1; previously named pS2) (HUGO Gene Nomenclature Committee; http://www.genenames. org) is a small cysteine-rich acidic secreted protein (Thim, 1997; Ribieras et al., 1998). It is constitutively and strongly expressed in the stomach, where it has a key role (Rio et al., 1988). Indeed, TFF1 is essential for the normal differentiation of the gastric glands (Bossenmeyer-Pourie et al., 2002; Karam et al., 2008). Moreover, by interacting with mucins, TFF1 participates in the correct organization of the mucus layer and in the gastric mucosa protection (Tomasetto et al., 2000). Transgenic mice overexpressing TFF1 have an increased resistance to ulceration (Playford et al., 1996). TFF1 is also expressed in the inflamed or damaged gastrointestinal tract, supporting the hypothesis that it mediates repair processes (Rio et al., 1991; Kjellev, 2009). Indeed, TFF1 promotes epithelial restitution after injury and protects the integrity of the epithelial barrier (Hoffmann, 2005). Moreover, TFF1 is also expressed, but to a lesser extent, by normal epithelial cells of numerous organs (eyes, lung, ovary and salivary gland) (Regalo et al., 2005; Madsen et al., 2007; Buron et al., 2008). To date, the TFF1 function during malignant processes is not clearly defined, as epithelial cell transformation might lead to downregulation of TFF1 expression (that is, in the stomach) or to the induction of TFF1 expression (that is, in various organs).

In the stomach, TFF1-deficient mice (TFF1-KO) develop antro-pyloric hyperplasia and dysplasia, leading to adenomas and intraepithelial or intramucosal carcinomas (Lefebvre et al., 1996). Epithelial progenitors are amplified and are more invasive (Karam et al., 2008). It has therefore been proposed that TFF1 functions as a gastric tumor suppressor gene. Strongly supporting this hypothesis, $50 \%$ of human gastric tumors are devoid of TFF1 because of deletions, mutations or methylation of the TFF1 gene (Ribieras et al., 1998; Katoh, 2003; Shi et al., 2006).

Breast cancer is a typical example of cancers overexpressing TFF1. As only a low expression is observed in the normal mammary gland (Poulsom et al., 1997; 
Madsen et al., 2007; Vestergaard et al., 2008), it has been suggested that, in breast cancers, high levels of TFF1 may have a pejorative function and that TFF1 should even be regarded as an oncogene (Perry et al., 2008). Supporting this hypothesis, in kidney and colon cancer cells overexpressing TFF1, TFF1 activates signaling pathways involved in cell survival, anchorage-independent growth, invasion and/or angiogenesis processes (Emami et al., 2001; Rodrigues et al., 2003, 2006). Furthermore, TFF1 has been associated with breast cancer bone metastases (Smid et al., 2006). However, contrary to this view, numerous data have also suggested a beneficial role of TFF1 expression in human breast cancers. TFF1 is a classical estrogen-regulated gene possessing a canonical estrogen response element on its promoter (Ribieras et al., 1998). Consequently, TFF1 is expressed in about $50 \%$ of breast primary tumors, most of them estrogen receptor (ER) positive, a tumor subclass of better prognosis (Dunnwald et al., 2007). TFF1 is also expressed in metastases derived from TFF1-positive primary tumors (Rio et al., 1987). It is an informative marker for the detection of micrometastases (Mikhitarian et al., 2005). Moreover, patients with $\mathrm{ER}^{+} / \mathrm{TFF}^{+}$primary tumors have a better prognosis than patients with $\mathrm{ER}^{+} / \mathrm{TFF}^{-}$tumors (Rio et al., 1987; Foekens et al., 1990), and TFF1 constitutes a potent marker of hormone-dependent breast tumors and of hormone-therapy responsiveness (Ribieras et al., 1998; Chenard et al., 2004). Finally, transgenic mice expressing TFF1 in their mammary glands do not show increased cell proliferation or tumor formation (Tomasetto et al., 1989). Thus, despite numerous studies, TFF1 physiopathological function in breast cancers remains controversial.

To further address this question, we performed TFF1 loss- and gain-of-function approaches using normal (immortalized), ER-positive and ER-negative malignant human mammary cell lines, and tumorigenesis experiments in nude mice and TFF1-KO mice. Collectively, our results favor a beneficial function of TFF1 during malignant processes in breast cancers.

\section{Results}

Generation of MCF10A normal breast cells, and $M D A-M B-231$ and MCF7 breast cancer cells constitutively expressing TFF1

To test the oncogenic properties of TFF1, the human immortalized normal breast cell line MCF10A and ERnegative breast cancer cell line MDA-MB-231, which do not express TFF1 (deFazio et al., 2000; Mackay et al., 2009), were stably modified using pQCXIP retroviral vectors containing or not hTFF1 complementary DNA (Figure 1a). Western blot analysis of cell extracts showed that the MCF10A/CTL (pQCXIP) control cells do not express TFF1, whereas MCF10A/TFF1 (pQCXIP hTFF1) cells displayed strong TFF1 protein expression. As expected, conditioned medium analysis showed that TFF1 was secreted only by MCF10A/
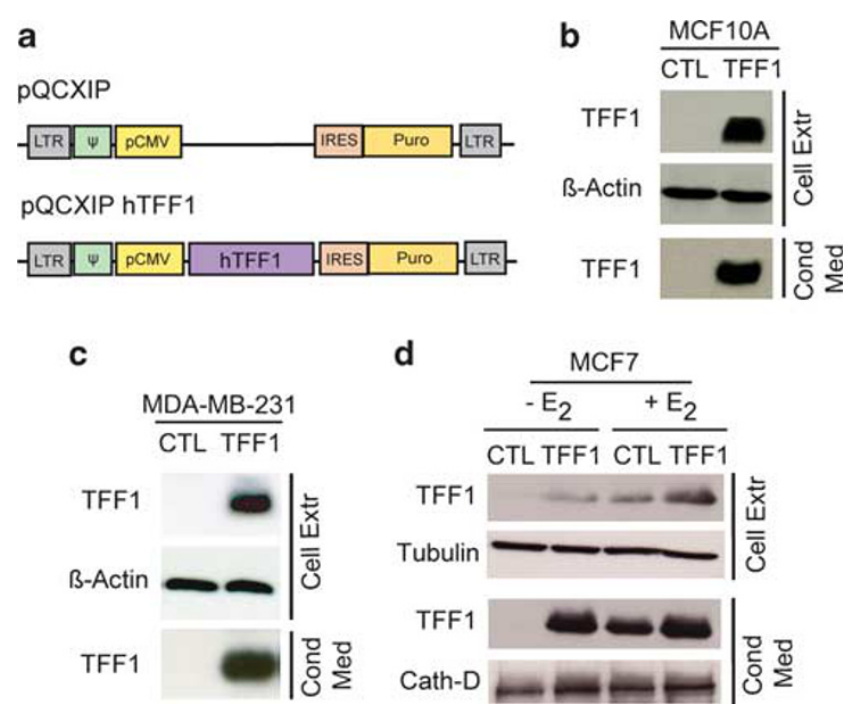

Figure 1 Induction of constitutive TFF1 expression in MCF10A, MDA-MB-231 and MCF7 breast epithelial cells. (a) pQCXIP and pQCXIP hTFF1 retroviral vectors. (b) Total proteins from wholecell lysates (Cell Extr) and conditioned medium (Cond Med) from MCF10A/CTL and MCF10A/TFF1 cells were separated by 10-20\% gradient SDS-polyacrylamide gel electrophoresis and subjected to TFF1 immunoblot analysis using the p28O2 antibody. MCF10A/TFF1 cells strongly expressed and secreted TFF1, whereas MCF10A/CTL cells were completely TFF1 negative. (c) Western blot showed that MDA-MB-231/TFF1 cells expressed and secreted TFF1, whereas MDA-MB-231/CTL cells remained TFF1 negative. (d) Western blot analysis of MCF7/CTL and MCF7/TFF1 cells shows that TFF1 is overexpressed regardless of E2 status. Note that, in the presence of E2, endogenous TFF1 is strongly expressed and secreted by MCF7/CTL cells. $\beta$-Actin, tubulin and Cath-D served as loading controls.

TFF1 cells (Figure 1b). Similarly, strong TFF1 expression and secretion were observed in MDA-MB-231/ TFF1 (pQCXIP hTFF1) cells, whereas MDA-MB-231/ CTL (pQCXIP) control cells were devoid of TFF1 (Figure 1c). To test the effect of forced TFF1 expression in an ER-positive breast cancer cell line, we established MCF7/TFF1 cells. MCF7 cells are known to express and secrete high endogenous TFF1 levels when cultured in the presence of estrogens (E2) (Ribieras et al., 1998) (Figure 1d, compare MCF7/CTL +/- E2). MCF7/ TFF1 expressed high amounts of TFF1. Thus, the pQCXIP hTFF1 retroviral vector efficiently induces TFF1 expression in MCF10A, MDA-MB-231 and MCF7 mammary cells.

pQCXIP hTFF1 expression enhances MCF10A, $M D A-M B-231$ and $M C F 7$ cell migration and invasion To test the functionality of our TFF1 gain-of-function cell models, we investigated the impact of TFF1 on cell migration and invasion, as numerous studies indicate that TFF1 favors these biological processes in normal and malignant conditions (Ribieras et al., 1998; Prest et al., 2002; Amiry et al., 2009). Using Transwell membranes, we observed that the migration of MCF10A/TFF1 cells was increased compared with MCF10A/CTL cells (Figure 2Aa; 2.9-fold, $P<0.001$ ). 
Similarly, the motility of MDA-MB-231/TFF1 cells was increased compared with MDA-MB-231/CTL cells (Figure 2Ab; 1.6-fold, $P<0.01$ ). Finally, MCF7/TFF1 cell migration was increased when cells were grown in the absence of E2 (no endogenous TFF1 expressed) (Figure 2Ac; 1.7-fold, $P<0.001)$. Cell invasion was assessed using Transwell membranes coated with Matrigel, a reconstituted basement membrane. The invasiveness of $\mathrm{MCF} 10 \mathrm{~A} / \mathrm{TFF} 1$ cells was increased compared with MCF10A/CTL cells (Figure 2Ba; 1.6fold, $P<0.001$ ), as that of MDA-MB-231/TFF1 cells compared with MDA-MB-231/CTL cells (Figure 2Bb; 1.3-fold, $P<0.05)$. MCF7/TFF1 cells showed increased invasiveness compared with $\mathrm{MCF} 7 / \mathrm{CTL}$, only in the absence of E2 (Figure 2Bc; 1.8-fold, $P<0.001$ ). Thus, TFF1 stimulates the migration and invasion in both normal and malignant human breast epithelial cells. Moreover, in MCF7/TFF1 cells, the impact of pQCXIP hTFF1 was observed only in the absence of E2, indicating that, in the presence of E2, endogenous TFF1 already has an optimal function (Figure 2Ac and $\mathrm{Bc}$ ).

pQCXIP hTFF1 expression does not modify MCF10A, $M D A-M B-231$ and $M C F 7$ cell proliferation or clonal cell growth in soft agar

We then studied the cell proliferative capacity that is dependent on TFF1 expression using the 3-(4,5dimethylthiazol-2-yl)-2,5-diphenyltetrazolium bromide (MTT) method. Cells were grown in $1 \%$ fetal calf serum. We observed that forced TFF1 expression had no effect, as MCF10A/CTL and MCF10A/TFF1 cells exhibited similar proliferative curves (Figure $3 \mathrm{Aa}$ ), such as MDA-MB-231/CTL and MDA-MB-231/TFF1 cells (Figure 3Ab), and MCF7/CTL and MCF7/TFF1 cells (Figure 3Ac). Both MCF7/CTL and MCF7/TFF1 proliferated very slowly in the absence of $\mathrm{E} 2$ as expected for E2-dependent cells (Figure 3Ac). MCF10A, MDAMB-231 and MCF7 cells stably modified for TFF1 expression were then used to determine the possible oncogenic function of TFF1 in vitro using a soft-agar anchorage-independent growth test that identifies transformed cells (Thullberg and Stromblad, 2008). As expected, the immortalized but not transformed MCF10A/CTL cells did not form colonies. No colonies were observed with MCF10A/TFF1 cells, demonstrating that TFF1 expression is not sufficient to transform MCF10A cells (Figure 3Ba). Moreover, MDA-MB-231/ CTL and MDA-MB-231/TFF1 cancer cells developed similar colony number (Figure 3Bb). Neither MCF7/ CTL nor MCF7/TFF1 developed colonies in the absence of E2, and similar colony numbers were observed in the presence of E2 (Figure 3Bc). Thus, forced TFF1 expression does not induce cell proliferation or improve the in vitro oncogenic properties in normal or malignant mammary epithelial cells.

pQCXIP hTFF1 expression does not modify in vivo tumorigenesis in the MCF7 xenograft model

To check the in vivo effect of forced TFF1, MCF7/CTL or MCF7/TFF1 cells were injected subcutaneously into nude mice in the absence or presence of E2. E2 was added in the drinking water (Mira et al., 2004). We studied the kinetics of tumor occurrence and tumor volume. In the absence of E2, no tumors developed. In the presence of E2, tumors developed but no statistical differences were observed between the cell lines (Figure $4 \mathrm{a}$ ). At the end of the experiment, $75 \%$ of MCF7/TFF1 and $85.7 \%$ of MCF7/CTL mice presented tumors. Moreover, tumor growth rates were similar regardless of their TFF1 status (Supplementary Figure S1A). Western blot (Figure 4b) and immunohistochemical analyses (Figure 4c) of the tumors confirmed high TFF1 expression levels in both MCF7/CTL (endogenous TFF1 expression) and MCF7/TFF1 (endogenous TFF1 plus pQCXIP-induced TFF1 expression) cells. Thus, in agreement with the in vitro soft-agar data, MCF7 tumorigenicity is not significantly modified in vivo, subsequent to pQCXIP hTFF1 expression.

\section{Generation of MCF7 and ZR75.1 breast cancer cells knocked down for endogenous TFF1 expression}

The second part of our study concerns TFF1 loss-offunction. This was achieved by downregulating endogenous TFF1, using shRNA strategy. Although TFF1 messenger RNA is a short messenger RNA, analysis allowed us to design five potential TFF1-specific shRNA sequences scattered along TFF1 messenger RNA (21 nucleotides each) (Figure 5a). MCF7 cells were stably modified using pLMP retroviral vectors expressing these shTFF1s or scramble shRNA (pLMP shTFF1\#1-5 and pLMP shScr, respectively; Figure 5b). As endogenous TFF1 was not expressed in the absence of E2 in MCF7 cells (Ribieras et al., 1998) (Figure 1d), all experiments were performed in the presence of E2. As expected, MCF7/shScr expressed high TFF1 levels, whereas MCF7/shTFF1\#1-5 exhibited from 50\% to more than $90 \%$ decrease in TFF1 expression and secretion, as shown by western blot analysis of cell extract and conditioned culture media (Figure 5c). shTFF1\#1 and shTFF1\#4 were the two most efficient and were chosen for further experiments. A second ER-positive cell line, ZR75.1, was similarly modified using pLMP shTFF1\#1, pLMP shTFF1\#4 and pLMP shScr vectors. Similar to MCF7 cells, both ZR75.1/shTFF1\#1 and ZR75.1/ shTFF1\#4 exhibited dramatic decrease in TFF1 expression and secretion (Figure 5d). Thus, the pLMP shTFF1\#1 and pLMP shTFF1\#4 retroviral vectors efficiently knock down TFF1 expression in MCF7 and ZR75.1 cells.

\section{Endogenous TFF1 knockdown reduces $M C F 7$ and ZR75.1 cell migration and invasion}

We investigated the impact of TFF1 knockdown in MCF7 and ZR75.1 cells on cell migration and invasion. Using Transwell membranes, we observed that the migration of MCF7/shTFF1\#1 and MCF7/shTFF1\#4 cells displayed a decrease in migration compared with MCF7/shScr cells (Figure 6Aa; twofold and threefold, respectively, $P<0.001)$. Similarly, the motility of ZR75.1/shTFF1\#1 and ZR75.1/shTFF1\#4 cells showed 
3264

A a
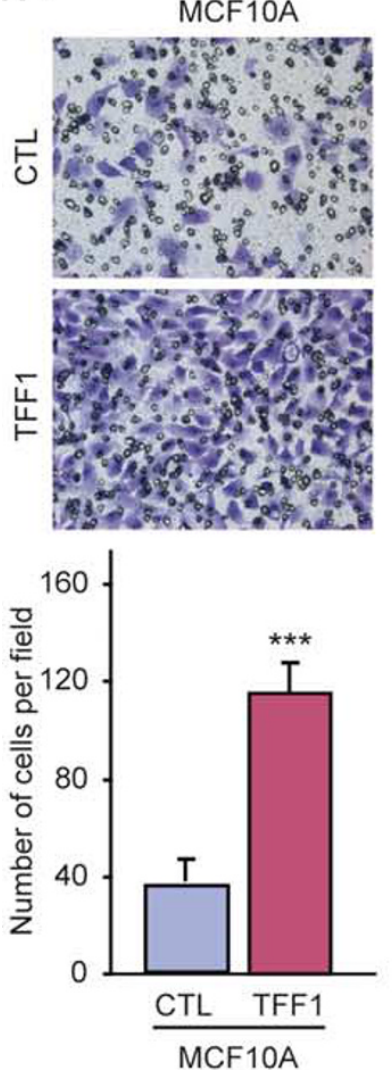

B a
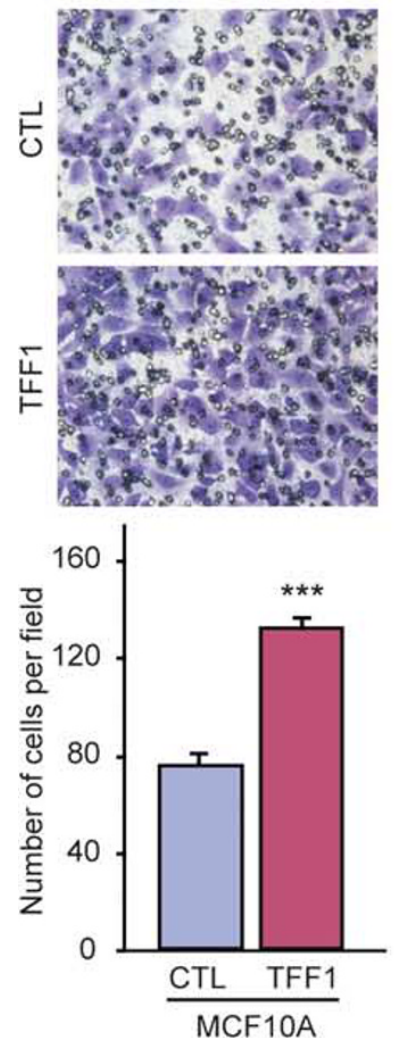
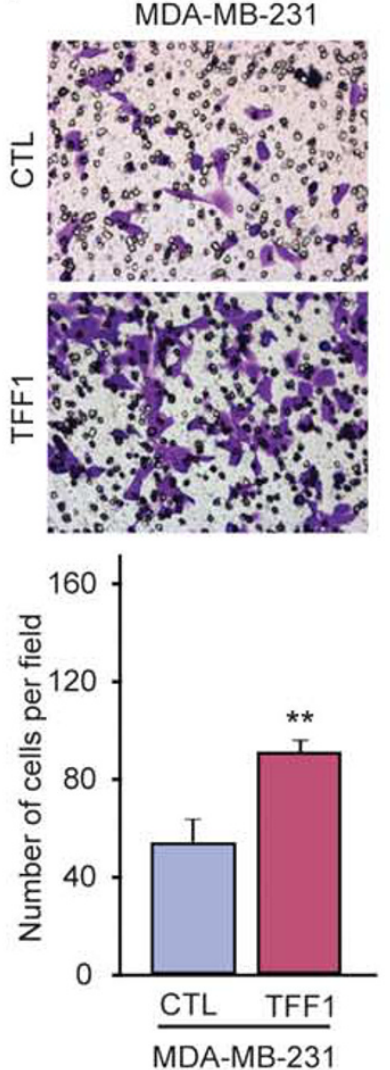

b
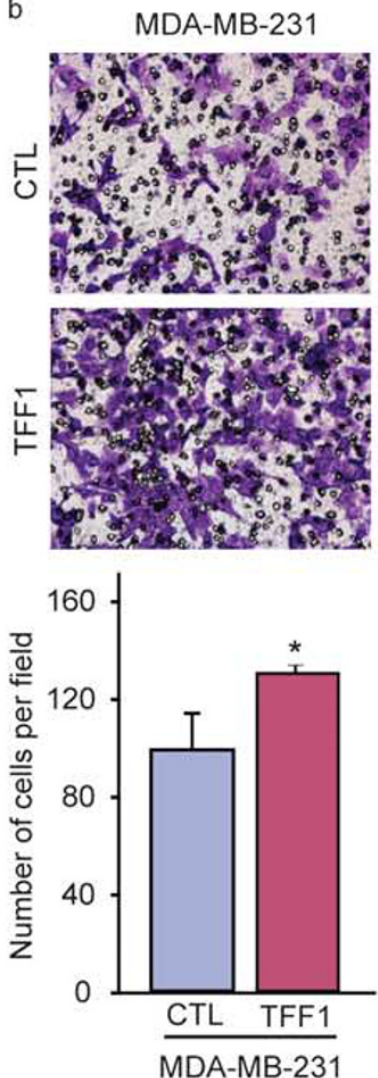
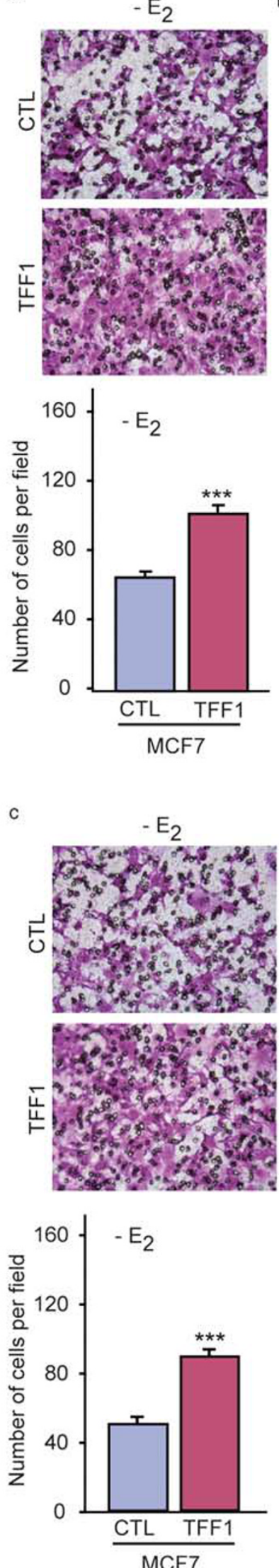

MCF7 $+\mathrm{E}_{2}$
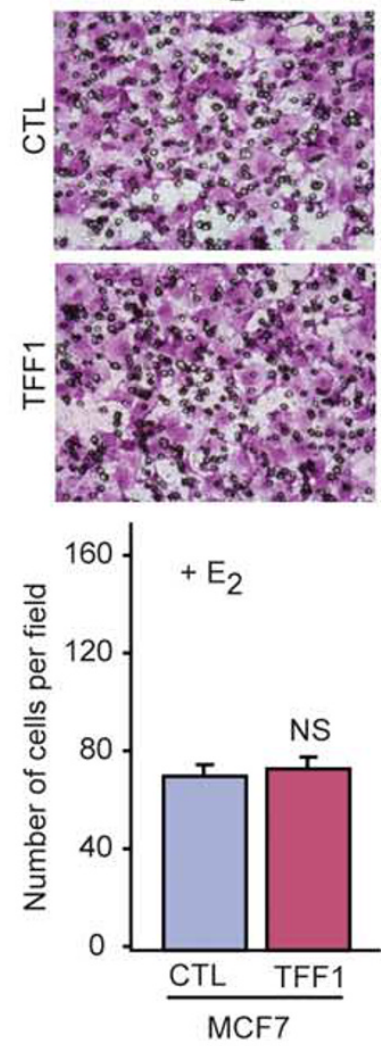

MCF7 $+E_{2}$
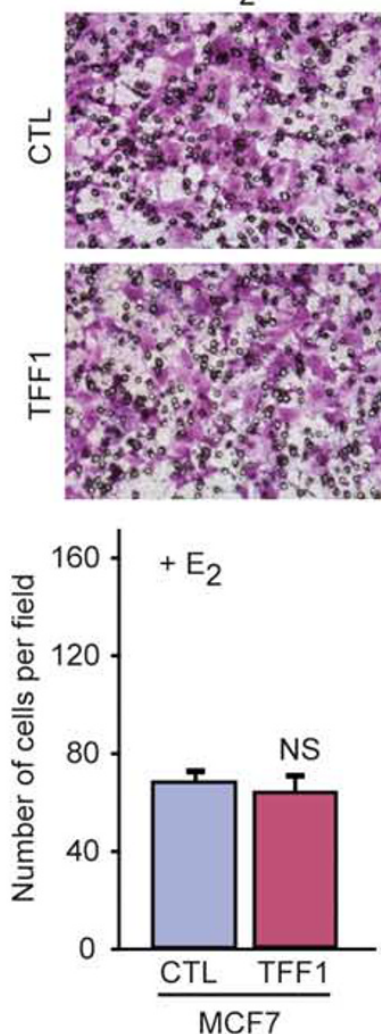
a decrease compared with ZR75.1/shScr cells (Figure 6Ab; twofold, $P<0.001$ ). Moreover, cell invasion through Matrigel-coated Transwell membranes of MCF7/shTFF1\#1 and MCF7/shTFF1\#4 cells were decreased compared with $\mathrm{MCF} 7 / \mathrm{shScr}$ cells
(Figure 6Ba; 1.8 -fold, $P<0.001$ and 1.5 -fold, $P<0.01$, respectively). Similarly, ZR75.1/shTFF1\#1 and ZR75.1/ shTFF1\#4 cell invasion was decreased compared with ZR75.1/shScr cells (Figure 6Bb; 1.6-fold, $P<0.001$ ). Thus, knockdown of endogenous TFF1 lowers migra-
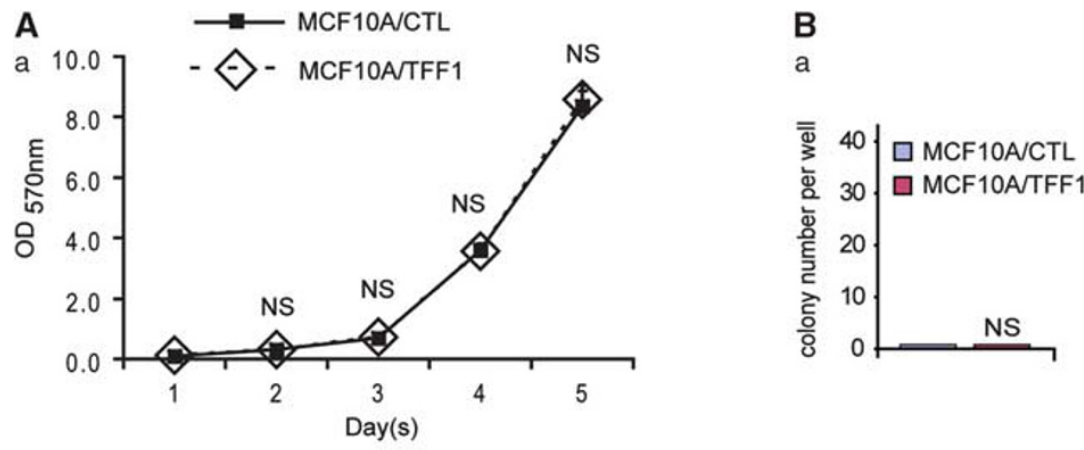

b
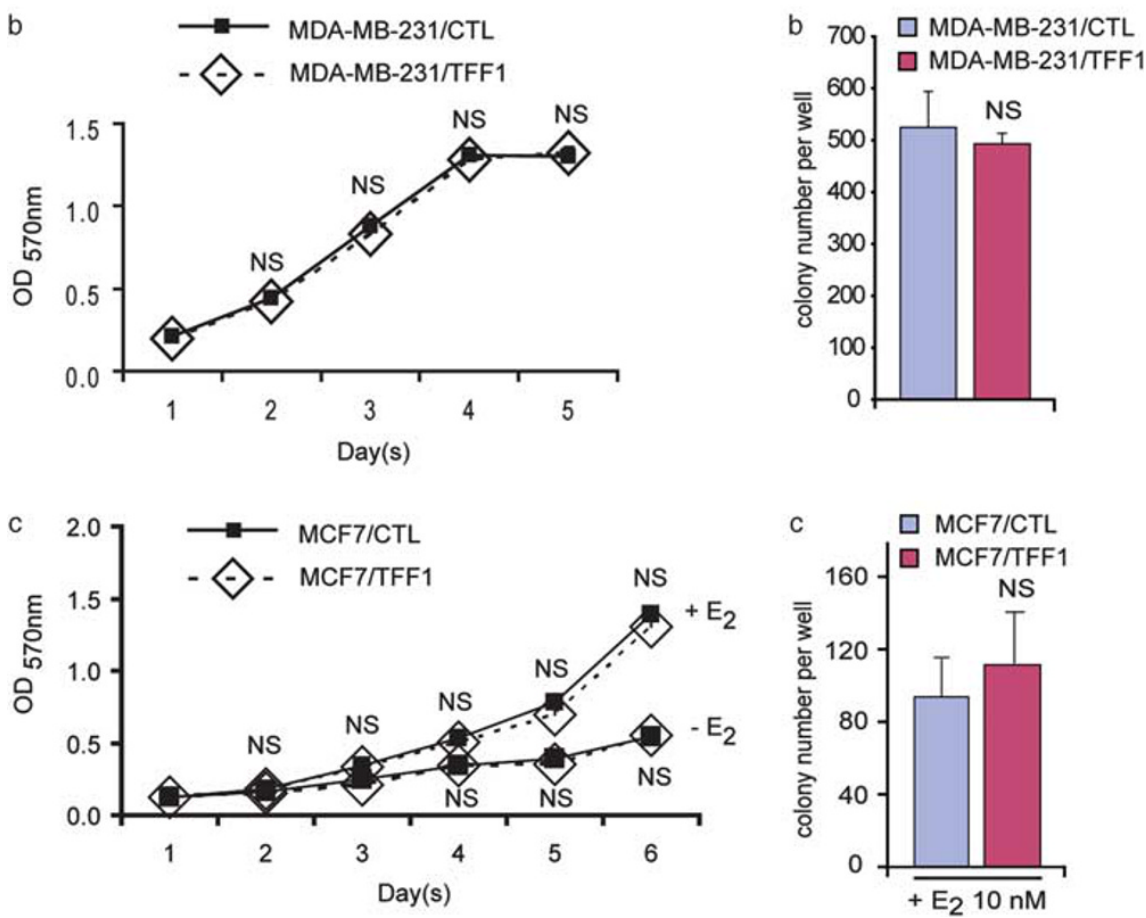

Figure 3 Impact of constitutive TFF1 on MCF10A, MDA-MB-231 and MCF7 cell proliferation and colony formation in soft agar. (A) cell proliferation: MCF10A/CTL and MCF10A/TFF1 (a), MDA-MB-231/CTL and MDA-MB-231/TFF1 (b) and MCF7/CTL and MCF7/TFF1 cells (c) were cultured for 5 days in culture medium containing $1 \%$ fetal calf serum, and counted using the MTT method. No significant differences (NS) were observed regardless of TFF1 status. Note that MCF7/TFF1 and MCF7/CTL cell proliferation were low in the absence of E2. (B) Cells were agar embedded. After 18 days, colonies were stained (crystal violet) and counted. (a) MCF10A/TFF1 and MCF10A/CTL did not form colonies. (b) MDA-MB-231/TFF1 and MDA-MB-231/CTL cells gave rise to colonies of similar number (NS). (c) In the absence of E2, MCF7/TFF1 and MCF7/CTL colony numbers were very low. However, in the presence of E2 (10 nM), the number of colonies increased in both MCF7/TFF1 and MCF7/CTL in a similar manner (NS). Histograms: mean \pm s.e. of triplicates.

Figure 2 Impact of constitutive TFF1 on MCF10A, MDA-MB-231 and MCF7 cell migration and invasion. (A) Crystal violet-stained migrated cells present at the lower face of the Transwell membranes were counted with an inverted microscope; (a) increased MCF10A/ TFF1 migration compared with MCF10A/CTL $(P<0.001)$; (b) similar results for MDA-MB-231/TFF1 versus MDA-MB-231/CTL cells $(P<0.01)$; (c) similar results for MCF7/TFF1 versus MCF7/CTL cells $(P<0.001)$; no effect was shown for MCF7/TFF1 cells in the presence of E2. (B) Invasive cells through matrigel-coated membranes were analyzed as in A. TFF1 expression increases invasion, regardless of the cell tested ( $\mathrm{a}$ and $\mathrm{c}, P<0.001 ; \mathrm{b}, P<0.05$ ). No effect was shown for MCF7/TFF1 cells in the presence of E2. Histograms: mean \pm s.e. of triplicates. NS, not significant. 
a

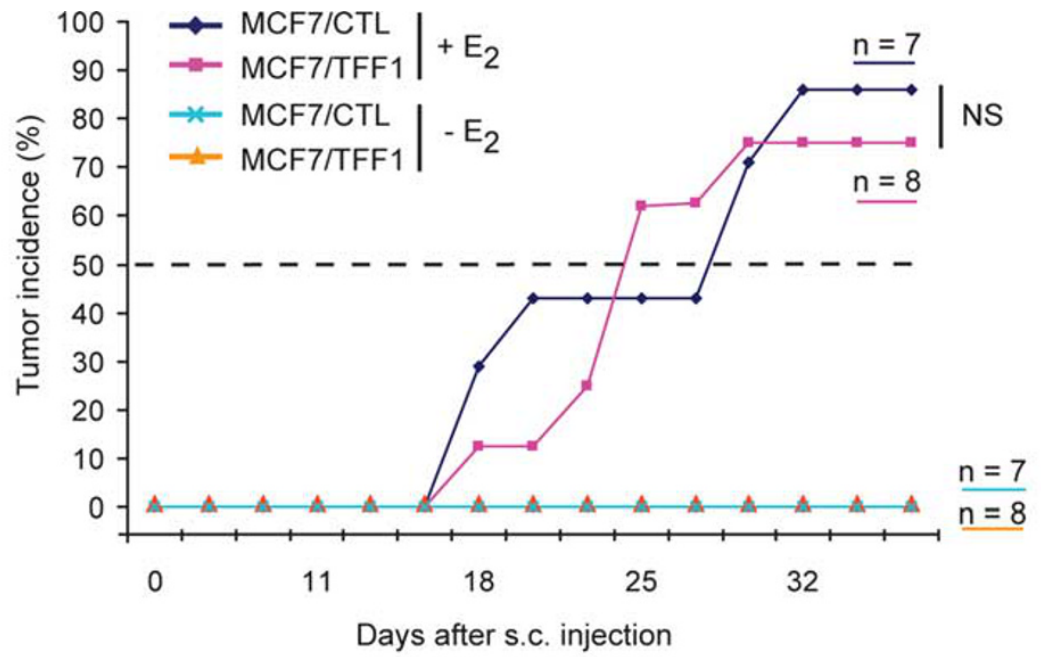

b

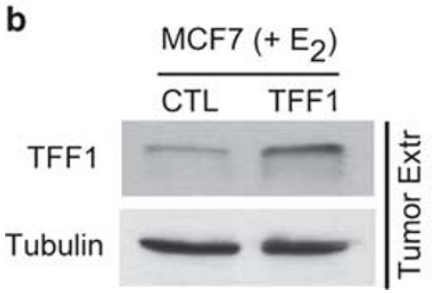

c $\mathrm{MCF} 7 / \mathrm{CTL}$
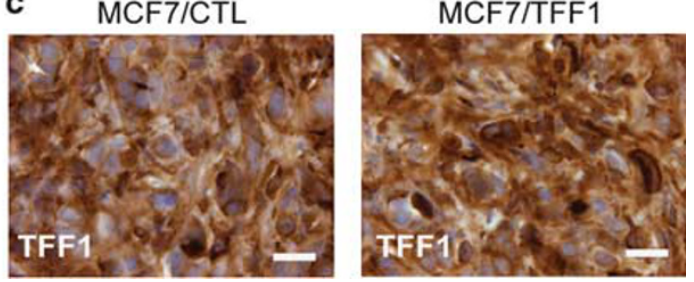

Figure 4 Impact of forced TFF1 expression on MCF7 cell tumorigenicity in nude mice. (a) Tumor occurrence after subcutaneous injection in nude mice of $10^{6}$ cells. Curves showed that MCF7/CTL and MCF7/TFF1 did not develop tumors in the absence of E2. In the presence of E2, both cell lines developed tumors in a similar manner (NS). (b) Western blot showed that MCF7/CTL tumor cells expressed TFF1 (endogenous TFF1), as well as MCF7/TFF1 (endogenous TFF1 plus pQCXIP TFF1). (c) Tumor immunohistochemistry confirmed TFF1 expression (brown). Bars: $30 \mu \mathrm{m}$.

tion and invasiveness of ER-positive breast cancer cells, confirming that TFF1 has a key role in these processes.

\section{Endogenous TFF1 knockdown does not modify MCF7 and ZR75.1 cell proliferation, but increases the clonal growth of MCF7 cells in soft agar}

TFF1 knockdown did not modify cell proliferation capacity, as no differences were observed between the proliferative curves of MCF7/shScr, MCF7/shTFF1\#1 and MCF7/shTFF1\#4 cells (Figure 7a). Similar data were obtained using the ZR75.1 cells (data not shown). We then tested the impact of TFF1 knockdown on MCF7/ shTFF1\#1 and MCF7/shTFF1\#4 soft-agar anchorageindependent growth. We observed increased colony numbers compared with MCF7/shScr (Figure 7b; $P<0.001$ and $P<0.01$, respectively). Thus, TFF1 knockdown does not modify cell proliferation but increases in vitro oncogenicity of ER-positive breast cancer cells.

\section{Endogenous TFF1 knockdown in MCF7 cells improves tumor formation in nude mice}

To check the in vivo effect of TFF1 loss-of-function, pools of MCF7/shScr or MCF7/shTFF1\#1 cells were injected subcutaneously into nude mice (two sets of 12 mice each). E2 was added in the drinking water (Mira et al., 2004). The delay for the first tumor occurrence was higher for MCF7/shScr than for MCF7/shTFF1\#1 tumors (12 versus 26 days after injection) (Figure 8a). Moreover, $50 \%$ of the injected mice developed MCF7/ shTFF1\#1 tumors after 28 days, whereas 47 days were necessary for MCF7/shScr tumors to reach the same incidence $(P<0.01)$. Finally, 60 days after injection, $90 \%$ of the mice injected with MCF7/shTFF1\#1 cells exhibited tumors versus $55 \%$ for MCF7/shScr cells. This remained true for 124 days after injection. However, once detected, tumor growth rates were similar regardless of their TFF1 status (Supplementary Figure S1B). Tumor immunohistochemical analysis confirmed very low TFF1 expression in MCF7/shTFF1\#1 cells compared with MCF7/shScr cells (Figure 8b). Thus, in agreement with the in vitro soft-agar data, MCF7 tumorigenicity is significantly increased in vivo, subsequent to TFF1 knockdown.

\section{Endogenous TFF1 reduces DMBA-induced tumorigenesis} in mice

We then tested the impact of endogenous TFF1 on chemically induced tumors in 12 wild-type and 12 TFF1-KO littermate females by intragastric administration once a week during 6 weeks of 7,12-dimethylbenz[a]anthracene (DMBA), a procarcinogen (Lefebvre et al., 1996; Masson et al., 1998). Twenty-two weeks after, mice were killed, and systematic histological examination of the liver, lung, mammary gland (all of 


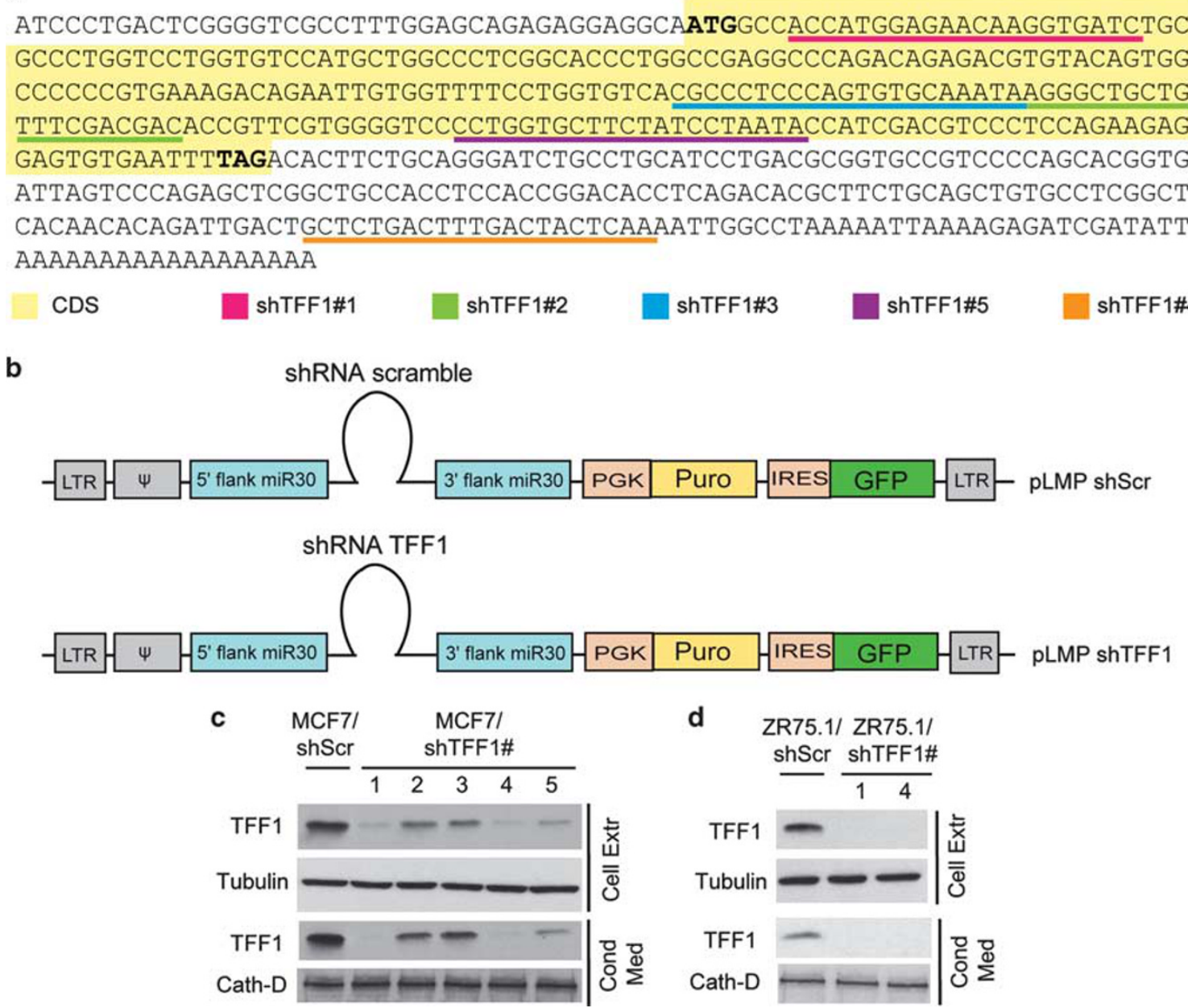

Figure 5 Knockdown of TFF1 expression in MCF7 and ZR75.1 breast epithelial cells. (a) TFF1 messenger RNA complete sequence; the ATG start site and the TAG stop codon are in bold, and the coding sequence (CDS) in yellow. Putative TFF1 shRNA sequences are underlined as indicated. (b) pLMP shScr and pLMP shTFF1 retroviral vectors. (c) Western blot analysis of cell extracts and conditioned medium showed that endogenous TFF1 protein levels were higher in MCF7/shScr than in all MCF7/shTFF1s cells. shTFF1\#1 and shTFF1\#4 were the most efficient in knocking TFF1 in MCF7 cells. (d) Similarly, ZR75.1/shTFF1\#1 and ZR75.1/ shTFF1\#4 showed a dramatic TFF1 decrease compared with ZR75.1/shScr. Tubulin and Cath-D are loading controls.

them) and ovary was performed for the presence of tumors. Table 1 recapitulates the results of one of the two independent experiments (each including 24 mice) that gave similar results. Two TFF1-KO mice died before the end of the experiments. In the mammary gland, a threefold increase in tumor incidence was observed in TFF1-KO mice, although this was not significant. Nevertheless, a strong and significant increase in tumor size was observed in TFF1-KO mice (4.4-fold; $P<0.01$ ). Moreover, all TFF1-KO mice and $50 \%$ of the wild-type mice exhibited malignant ovarian tumors $(P<0.01)$. Ovaries never presented more than one tumor. The size of ovarian carcinoma was smaller in wild-type mice (mean: 1.82 versus $3.75 \mathrm{~mm} ; P<0.001$ ). In the lung, although tumor incidence was similar, the number of tumors per mouse was higher in the TFF1KO mice (mean: 3.5 versus $1.4 ; P<0.001$ ). Finally, no liver tumors were detected in all mice regardless of TFF1 status. Thus, endogenous TFF1 reduces in vivo mouse tumor development and/or progression, not only in the mammary gland but also in other organs, such as the ovary and the lung.

\section{Discussion}

This study was undertaken to bring additional clues concerning the function of TFF1 in breast carcinomas. Indeed, its physiopathological role in this disease is not well understood to date. We showed that TFF1 promotes cell migration and invasion in all cells tested. Moreover, TFF1 gain-of-function experiments performed in ER-negative or ER-positive mammary cells showed that TFF1 does not exhibit in vitro and in vivo pro-tumor properties. Conversely, TFF1 loss-of-function performed in ER-positive mammary cells showed in vitro and in vivo anti-tumor effects for TFF1. The lower DMBA-induced tumor development observed in TFF1-KO mice strongly supports these results. 
A
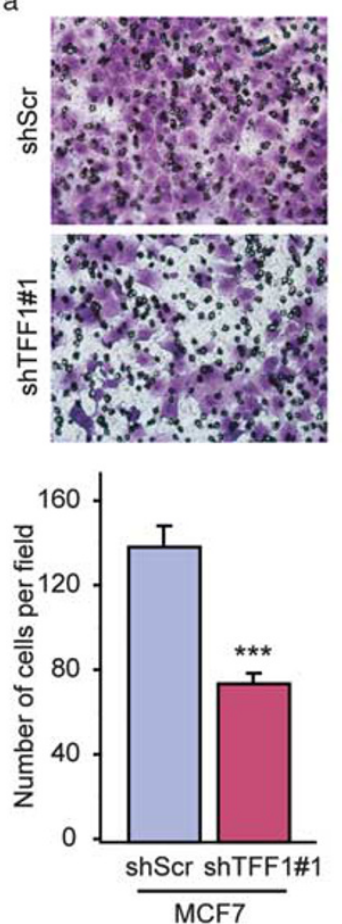

B
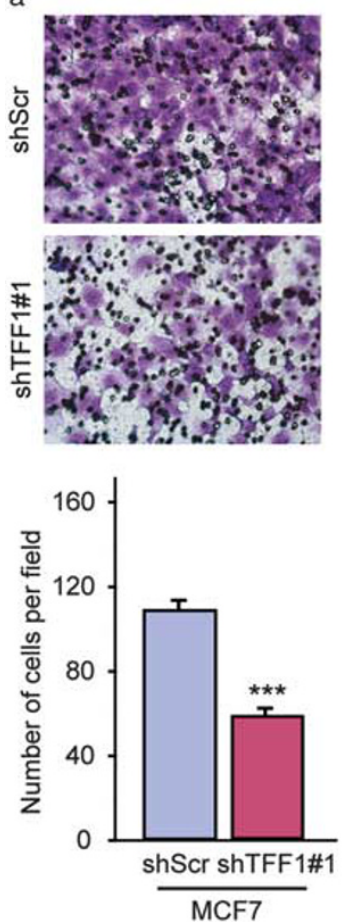

MCF7

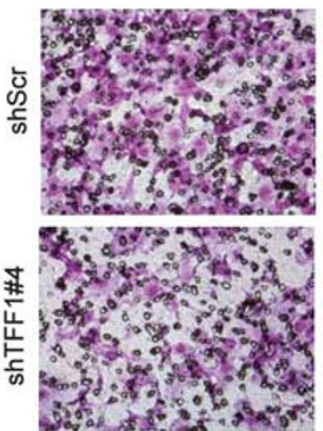

b

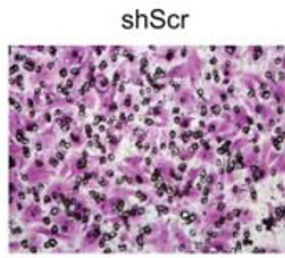

ZR75.1

shTFF1\#1
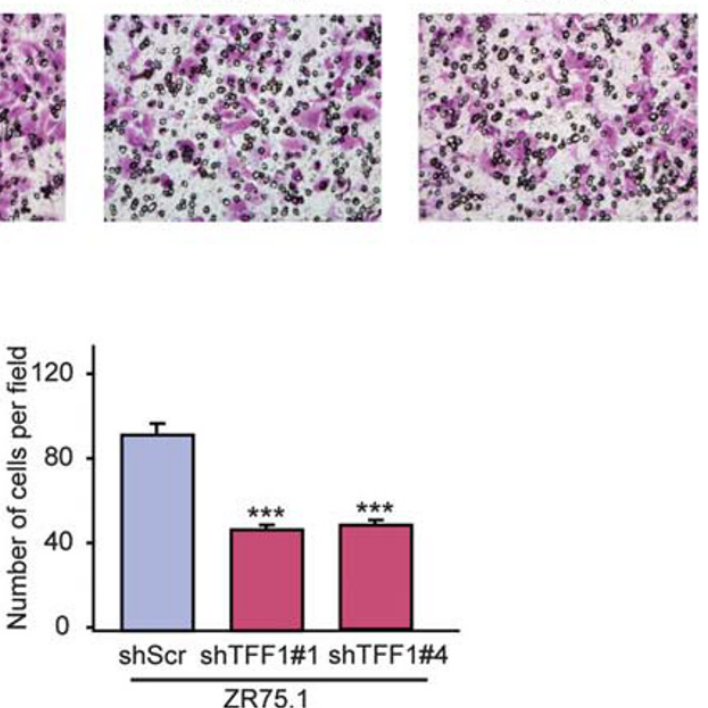

b
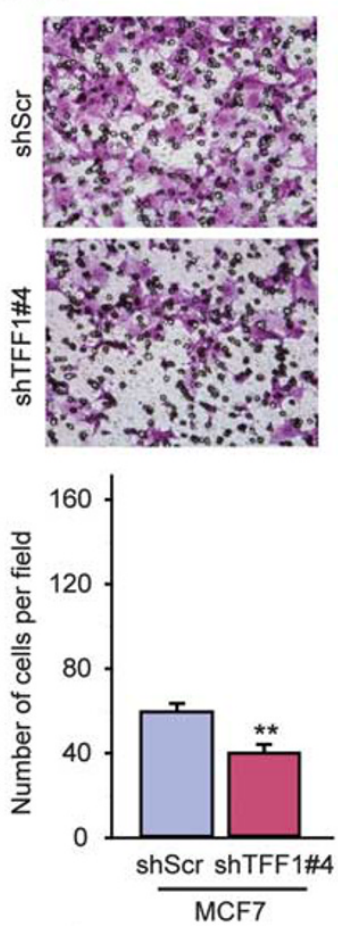

ZR75.1

shTFF1\#1
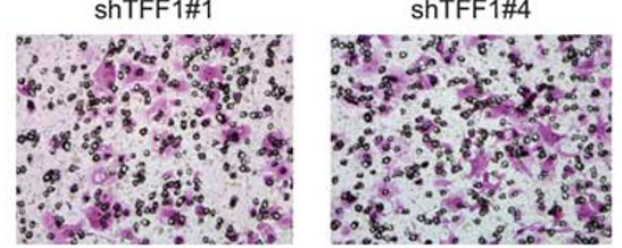

Figure 6 Impact of TFF1 knockdown on MCF7 and ZR75.1 cell migration and invasion. (A) Number of crystal violet-stained migrated cells present at the lower face of the Transwell membranes; (a) decreased MCF7/shTFF1\#1 and MCF7/shTFF1\#4 cell migration compared with MCF7/shScr $(P<0.001)$; (b) similar results for ZR75.1/shTFF1\#1 and ZR75.1/shTFF1\#4 compared with ZR75.1/shScr $(P<0.001)$. (B) Number of invasive cells through matrigel-coated membranes; (a) decreased MCF7/shTFF1\#1 and MCF7/shTFF1\#4 cell invasion compared with MCF7/shScr $(P<0.001$ and $P<0.01$, respectively); (b) similar results for ZR75.1/ shTFF1\#1 and ZR75.1/shTFF1\#4 compared with ZR75.1/shScr $(P<0.001)$. Histograms: mean \pm s.e. of triplicates. 
It has been suggested that TFF1 might be a Janus factor in cancers depending on the tissue. On the one hand, TFF1 acts as a gastric tumor suppressor gene. TFF1-KO mice therefore develop antro-pyloric adenomas and carcinomas (Lefebvre et al., 1996; Karam et al., 2008). Accordingly, TFF1 expression is reduced in human gastric carcinomas due to TFF1 gene alterations (Ribieras et al., 1998; Katoh, 2003; Shi et al., 2006). On the other hand, TFF1 is expressed in numerous other a
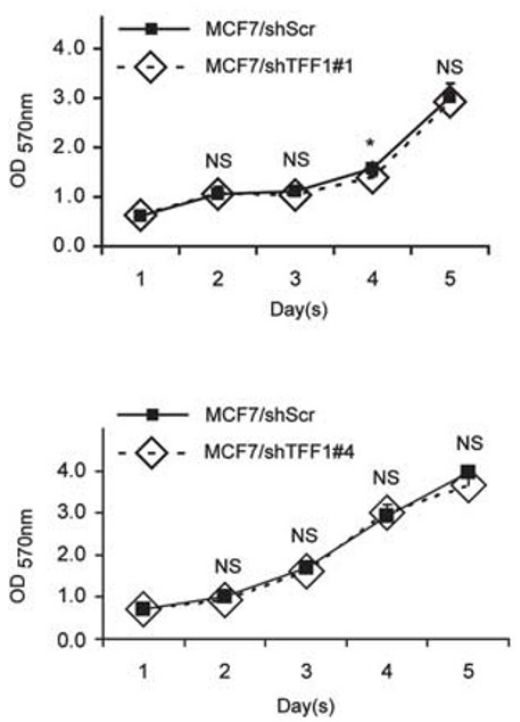
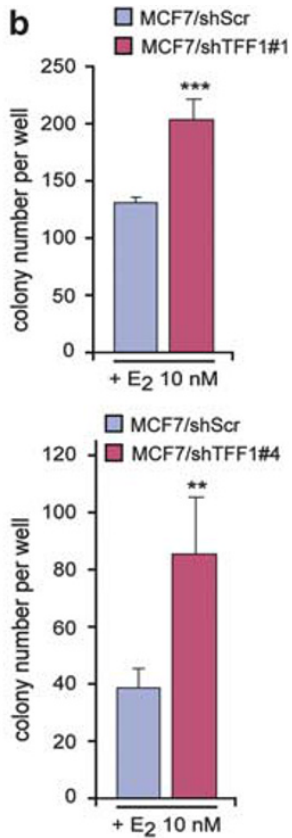

Figure 7 Impact of TFF1 knockdown on MCF7 cell proliferation and colony formation in soft agar. (a) Using the MTT method, no differences (NS) were observed between MCF7/shScr, MCF7/ shTFF1\#1 and MCF7/shTFF1\#4 cell proliferation. (b) MCF7/ shTFF1\#1 and MCF7/shTFF1\#4 developed more colonies in soft agar than MCF7/shScr cells $(P<0.001$ and $P<0.01$, respectively). Histograms: mean \pm s.e. of triplicates. normal epithelia. Thus, TFF1 messenger RNA and/or protein have been shown to be focally expressed by normal mammary ducts (Poulsom et al., 1997; Wilson et al., 2006; Madsen et al., 2007; Vestergaard et al., 2008), and TFF1 is a human milk component (Vestergaard et al., 2008). However, in breast cancers, as in various other cancers, TFF1 expression is not downregulated as observed in gastric tumors, but strongly induced (Ribieras et al., 1998; Regalo et al., 2005), suggesting a possible function as an oncogene (Perry et al., 2008).

This question is important as the usefulness of TFF1 as a pharmacological treatment on gut inflammatory disorders, notably following chemo- or radio-therapies, is being investigated (Katoh, 2003; Kjellev, 2009). However, a therapeutic potential for antagonizing TFF1 has been recently proposed for breast cancer treatment (Perry et al., 2008). Thus, TFF1 breast function needs to be clarified, in order to evaluate the benefits and side effects of such therapies for the whole individual.

In the TFF1-negative normal immortalized MCF10A human breast cell line, TFF1 gain-of-function did not modify anchorage-dependent or -independent cell proliferation, indicating that TFF1 is unable to induce cell cycle, or to confer oncogenic potential in normal mammary cells. Consistently, our previous in vivo studies showed no obvious structural or functional mammary gland alterations, or tumors in transgenic mice specifically expressing TFF1 in their mammary glands (Tomasetto et al., 1989). Moreover, cell migration and invasion were dramatically increased in MCF10A/TFF1 compared with MCF10A/CTL cells, confirming that TFF1 is a motogenic factor. Interestingly, motogenic and invasive activities are required during mammary gland morphogenesis (Andrew and Ewald, 2010), suggesting that TFF1 might be involved in mammary gland ontogenesis and/or remodeling. However, as TFF1-KO mice did not exhibit obvious mammary gland alterations (Lefebvre et al., 1996), this function may be compensated by another protein(s).
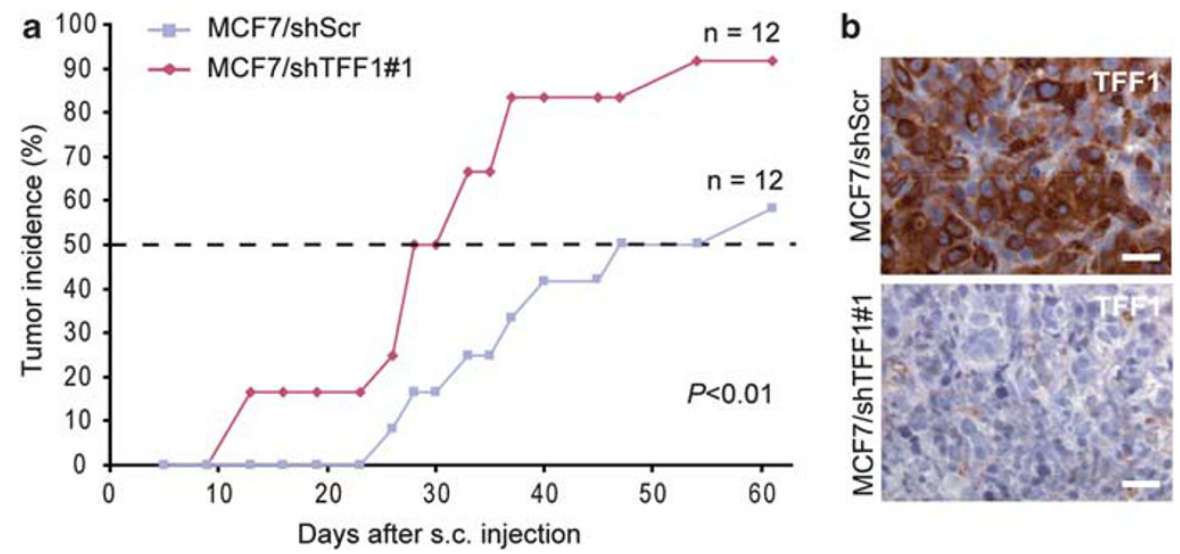

Figure 8 Impact of TFF1 knockdown on MCF7 cell tumorigenicity in nude mice. (a) Tumor occurrence after subcutaneous injection in nude mice of $2.5 \times 10^{5}$ cells in the presence of E2. Curves showed that MCF7/shTFF1\#1 tumors appeared earlier, and that their incidence was higher than for MCF7/shScr tumors. (b) TFF1 tumor immunohistochemistry showed that MCF7/shScr tumor cells strongly expressed TFF1, whereas only a few MCF7/shTFF1\#1 tumor cells were TFF1 positive (brown). Bars: 30 microns. 
Table 1 Comparison of DMBA-induced tumors in wild-type and TFF1-KO mice

\begin{tabular}{|c|c|c|c|c|c|c|}
\hline \multirow[t]{2}{*}{ Organs } & \multicolumn{2}{|c|}{ Tumor incidence } & \multicolumn{2}{|c|}{ Size } & \multicolumn{2}{|c|}{ Number per mouse } \\
\hline & Wild type & $T F F 1-K O$ & Wild type & $T F F 1-K O$ & Wild type & $T F F 1-K O$ \\
\hline Mammary gland & $2 / 12(17 \%)$ & $5 / 10(50 \%)$ & 1.13 & $5^{* *}$ & 2 & 1.5 \\
\hline Ovary & $6 / 12(50 \%)$ & $10 / 10(100 \%)^{\mathrm{b}, * *}$ & 1.82 & $3.75 * * *$ & 1 & 1 \\
\hline Lung & $9 / 12(75 \%)$ & $10 / 10(100 \%)$ & 0.45 & 0.55 & 1.4 & $3.5^{* * *}$ \\
\hline Liver & $0 / 12(0 \%)$ & $0 / 10(0 \%)$ & - & - & - & - \\
\hline
\end{tabular}

Abbreviations: DMBA, 7,12-dimethylbenz[a]anthracene; TFF1, trefoil factor 1.

Histological examination of mammary glands, ovary, lung and liver from TFF1-KO and wild-type littermate mice, 22 weeks after DMBA intragastric gavages. Tumor incidence, size and/or number were higher in TFF1-KO than in wild-type mice. The liver never developed tumors.

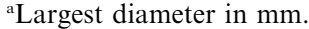

${ }^{\mathrm{b}}$ Two mice died before the end of the experiment.

$* * P<0.01, * * * P<0.001$

To study the impact of TFF1 in the context of breast malignancy, we used the TFF1-negative MDA-MB-231, and TFF1-positive MCF7 and ZR75.1 cell lines. All were TFF1-independent for their anchorage-dependent proliferation, confirming that TFF1 did not accelerate cell cycle, in agreement with previous MCF7 data (Kida et al., 1993). MDA-MB-231/TFF1 and MDA-MB-231/ CTL cells produced similar numbers of clones in soft agar. Moreover, forced TFF1 expression in MCF7 cells in the absence of E2 does not induce cell proliferation or colony formation. In the presence of E2, both MCF7/ CTL and MCF7/TFF1 cells showed increased cell proliferation and colony formation but at similar levels, indicating that these effects are not due to TFF1 but to other E2-regulated molecule(s). Moreover, forced TFF1 expression in MCF7 has no effect on tumor development in nude mice in the presence or absence of E2. Together, these results indicate that TFF1 has no oncogenic properties in ER-negative or ER-positive breast cancer cells. By contrast, MCF7/shTFF1\#1 cells, whose endogenous TFF1 levels were dramatically reduced, exhibited higher clonal growth in soft agar than MCF7/shScr control cells. Thus, TFF1 reduces the in vitro oncogenicity of MCF7 cells. Accordingly, the incidence of tumors from MCF7/shTFF1\#1 xenografts in nude mice was higher than from MCF7/shScr xenografts, showing that TFF1 negatively regulates tumor development in vivo. This result was confirmed by a second approach to test the oncogenic potential of endogenous TFF1 in vivo. DMBA-induced tumorigenesis in TFF1-KO mice led to higher mammary gland tumor incidence, both in number and size, compared with wild-type mice. Moreover, similar protective effects of TFF 1 were observed in the ovary and the lung. Thus, TFF1 might exert a common function during tumor development/progression, regardless of organ. In contrast, a recent study reports that TFF1 enhances in vitro and in vivo oncogenic capacity of mammary carcinoma cells. These authors concluded that TFF1 is an oncogene and that anti-TFF1 might represent a new therapeutical approach for breast cancers (Amiry et al., 2009). These discrepancies between our results might result from differences in cell lines and experimental procedures used (for example, siRNA versus shRNA,
E2 status of culture media, orthotopic versus ectopic xenografts).

TFF1 favors MDA-MB-231, MCF7 and ZR75.1 migration and invasion, two generic TFF1 functions shared by normal and malignant epithelial cell lines (Prest et al., 2002; Thuwajit et al., 2007; Tosco et al., 2010). As cellular invasion and migration participate in invasive processes, these data might suggest that TFF1 favors tumor spreading and metastasis development. However, the assumption of TFF1 as a metastatic factor should be re-examined given the following evidences. First, TFF1 exerts both migration/invasion and tumor suppressor functions in the stomach. Second, highly metastatic human breast cancer cell lines (for example, SK-BR3, MDA-MB-231) do not express TFF1, whereas low-invasive cells (for example, MCF7 and ZR75.1) do. Third, it has been reported that soluble motogens may have an effect on the balance between cancer cell motility and proliferation, and that cell proliferation and migration are mutually exclusive (Giese et al., 2003). Fourth, although TFF1 is a human milk component (Vestergaard et al., 2008), epidemiological studies report a protective effect of long-term suckling against breast cancers (Press and Pharoah, 2010). Fifth, among published clinical studies, more have indicated that patients with TFF1-positive primary breast tumors have better outcome (Rio et al., 1987; Foekens et al., 1990; Poulsom et al., 1997; Ribieras et al., 1998; Crosier et al., 2001; Corte et al., 2006; Lacroix, 2006; Surowiak et al., 2006; Scott et al., 2007; Markicevic et al., 2008; Stotter and Walker, 2009), than worse outcome (Crosier et al., 2001; Smid et al., 2006; Tjensvoll et al., 2009).

Although TFF1 inducing factors vary depending on the tissue and/or their malignant status, for example, gastrin in the normal stomach (Khan et al., 2003) and E2 in breast tumors (Ribieras et al., 1998), it might be hypothesized that TFF1 always exerts the same function(s). In this context, we propose that TFF1 favors cell differentiation. Indeed, TFF1 limits gut-cell proliferation and apoptosis, and favors cell differentiation (Tomasetto and Rio, 2005; Karam et al., 2008). Moreover, differentiation and motility are concomitant events of normal gastro-intestinal epithelial cells. For example, 
in gastric cells, eupatilin-induced cell-cycle arrest and differentiation are correlated with TFF1 overexpression (Choi et al., 2009). TFF1 also favors airway (Hoffmann, 2007) and conjunctival (Buron et al., 2008) epithelium differentiation. Finally, TFF1-expressing primary breast tumors exhibit higher tumor differentiation compared with those devoid of TFF1 (Rio et al., 1987; Foekens et al., 1990; Ribieras et al., 1998; Corte et al., 2006; Surowiak et al., 2006; Markicevic et al., 2008).

Collectively, these data indicate that TFF1 does not act as an oncogene in the mammary gland, but, conversely, exerts a beneficial function during malignant processes in breast cancers.

\section{Materials and methods}

\section{Retroviral vectors}

TFF1 gain-of-function: full-length human TFF1 complementary DNA was inserted in EcoRI-digested pQCXIP vector (Clontech, Saint-quentin, France) (pQCXIP hTFF1); control, empty pQCXIP vector (Figure 1a). TFF1 loss-of-function: complementary oligonucleotides of hTFF1 target sequences were cloned in $X h o \mathrm{I} / E c o \mathrm{RI}$-digested pLMP retroviral vector (Dickins et al., 2005) (pLMP shTFF1); control vector: $5^{\prime}$-CCA GTCGCCATTATAATGCAA-3' scramble sequence (pLMP shScr) (Figures 5a and b). Positive clones were sequenced.

\section{Cell culture and viral infection}

MCF10A, MDA-MB-231, MCF7 and ZR75.1 human mammary cells were grown in appropriate media (American Type Culture Collection, Rockville, MD, USA). Retroviruses were generated by co-transfection of $\mathrm{pLMP}$ or $\mathrm{pQCXIP}$ vector with pCL-Ampho vector (Imgenex, San Diego, CA, USA) into BOSC23 retroviral packaging cell line (Fugene 6 Reagent, Roche, Mannheim, Germany). Viral particles were collected $48 \mathrm{~h}$ after transfection. After retroviral infection $(10 \mu \mathrm{g} / \mathrm{ml}$ polybrene, $20 \mathrm{~mm}$ 2-[4-(2-hydroxyethyl)piperazin-1-yl]ethanesulfonic acid), selected cells $(0.5 \mu \mathrm{g} / \mathrm{ml}$ puromycin $)$ were pooled for further use. Medium devoid of E2: charcoal dextrantreated fetal calf serum, phenol red-free (E2-like molecule); medium plus E2: oestradiol $10 \mathrm{~nm}$.

\section{Western blot}

For cell extract, after washing, cells were resuspended in lysis buffer (50 mu Tris- $\mathrm{HCl} \mathrm{pH} 7.5,150 \mathrm{~mm} \mathrm{NaCl}, 1 \mathrm{~mm}$ EDTA, $1 \%$ Triton X-100, $1 \times$ protease inhibitor cocktail). After three freeze/thaw cycles, lysates were centrifuged and supernatants mixed with SDS buffer. On 10-20\% gradient SDS-polyacrylamide gel electrophoresis, $20 \mu \mathrm{g}$ of protein or $25 \mu \mathrm{l}$ of medium (1.4 м $\beta$-mercaptoethanol) was analyzed. After electrotransfer, nitrocellulose membranes (Schleicher and Schuell, Dassel, Germany) were blocked (phosphate-buffered saline, 5\% nonfat dry milk, 0.1\% Tween 20). Anti-TFF1 (Rio et al., 1988) (p28O2; 1:10 000; Euromedex, Illkirch, France), anti- $\beta$-actin (1:10 000; Sigma-Aldrich, StLouis, MO, USA), anti-tubulin and anti-cathepsin D (Cath-D) (Capony et al., 1989) (1:10000 and 1:2000, respectively; Santa-Cruz Biotechnology, Santa Cruz, CA, USA) primary antibodies, peroxidase-conjugated secondary antibody (1:10000) and chemiluminescent substrate were used.

\section{Migration and invasion}

The lower Transwell chamber (Costar, Dutscher, Brumath, France) contained cell appropriate medium (10\% fetal calf serum, $2 \%$ bovine serum albumin as chemoattractants). Cells in appropriate medium $(0.2 \%$ bovine serum albumin $)$ were seeded onto membranes of the upper Transwell chamber ( $6.5 \mathrm{~mm}$ diameter, $8 \mu \mathrm{m}$ pores) coated (invasion) or not (migration) with matrigel $\left(30 \mu \mathrm{g} / \mathrm{cm}^{2}\right) ;$ MCF10A $\left(2.5 \times 10^{4}\right.$ cells, 16h), MDA-MB-231 $\left(4 \times 10^{4}\right.$ cells, $\left.24 \mathrm{~h}\right)$, MCF7 $\left(10^{5}\right.$ cells, MCF7/shTFF1\#1 72h, MCF7/shTFF1\#4 48 h, MCF7/ TFF1 48 h) or ZR75.1 (10 cells, 72 h). For MCF7 and ZR75.1, medium also contained epidermal growth factor $(200 \mathrm{ng} / \mathrm{ml})$ (Doll et al., 2005). After incubation, cells were ethanol-fixed and stained (crystal violet). Cells at the membrane upper face were scraped and those on four fields of the lower face counted using an inverted microscope.

\section{Cell proliferation}

Cells were seeded on six-well plates. MCF10A and MDA-MB$231\left(5 \times 10^{3}\right.$ cells per well), MCF7 $\left(2 \times 10^{4}\right.$ cells per well $)$ and ZR75.1 $\left(4 \times 10^{4}\right.$ cells per well $)$ were cultured 5 days (appropriate culture medium, $1 \%$ fetal calf serum). Cell number was measured using MTT method at OD $570 \mathrm{~nm}$ (BossenmeyerPourie et al., 2002).

\section{Soft-agar growth}

Basal gel consisted of $1 \%$ agar (Sigma, St Louis, MO, USA) in appropriate medium, and upper gel consisted of $10^{3}$ cells mixed in $0.7 \%$ agar in appropriate cell medium. After 18-day culture, stained colonies (crystal violet) were visualized (MacroFluo, Leica Microsystems (Wetzlar, Germany); bright field; camera CoolSnap CF; Photometrics (Tucson, AZ, USA)). Colony number was quantified (MetaMorph, Molecular Devices, Sunnyvale, CA, USA).

\section{Tumorigenesis in nude mice}

TFF1 gain-of-function: $10^{6}$ cells $(50 \mu \mathrm{l}$ phosphate-buffered saline $1 \times)(\mathrm{MCF} 7 / \mathrm{CTL}, 7$ mice per set; MCF7/TFF1, 8 mice per set) were subcutaneously injected into the back of 8-weekold BALB/c nu/nu female mice (Charles River Laboratories, Wilmington, MA, USA) treated or not with E2 in drinking water $(1 \mu \mathrm{g} / \mathrm{ml}$; Sigma-Aldrich) (Mira et al., 2004). TFF1 lossof-function: similar experiments were performed using $2.5 \times 10^{5} \quad(50 \mu \mathrm{l}$ phosphate-buffered saline $1 \times)$ MCF7/ shTFF1\#1 or MCF-7/shScr cells (E2 in drinking water) (12 mice per set). Mice were examined every 3 days for tumor appearance. Tumor volume was calculated using the formula volume $=\pi \times$ width $^{2} \times$ length $/ 6$. Animal experiments were conducted in accordance with the National Institutes of Health's Guide for the Care and Use of Laboratory Animals.

\section{DMBA-induced tumorigenesis in TFF1-KO mice}

TFF1-KO and wild-type littermate $129 /$ Svj 8-week-old females (Lefebvre et al., 1996) were given weekly $500 \mu \mathrm{g}$ DMBA (Sigma-Aldrich) $(200 \mu$ l corn oil) by intragastric gavage, for 6 consecutive weeks (Masson et al., 1998). Twenty-two weeks after, animals were killed. Mammary glands ( 10 glands for each mouse), ovaries, lungs and liver were collected and fixed in phosphate-buffered formalin $(4 \%)$ and paraffin embedded. Tumor number and size were evaluated on five sections taken at the largest part of the surgical pieces.

\section{Histological analysis and immunohistochemistry of tumors}

Histological examination was performed on hematoxylineosin-stained paraffin sections under light microscope. For TFF1 immunohistochemistry, p28O2 anti-TFF1 monoclonal antibody (1:200; Euromedex, Illkirch, France) and a perox- 
idase-antiperoxidase system (Dako, Glostrup, Denmark) were used.

\section{Quantitative and statistical analyses}

At least three independent experiments were performed. Statistical differences were evaluated using student's $t$-test or $\chi^{2}$-test, and $P$-values lower than 0.05 were considered as significant. ${ }^{*} P<0.05 ; * * P<0.01 ; * * * P<0.001$.

\section{Conflict of interest}

The authors declare no conflict of interest.

\section{Acknowledgements}

We would like to thank Corinne Wendling for technical help, and Emmanuelle Liaudet and Susan Chan for helpful discussion. This work was supported by funds from the Institut National de la Santé et de la Recherche Médicale, the Centre National de la Recherche Scientifique, the Hopital Universitaire de Strasbourg, the Association pour la Recherche sur le Cancer, and the Ligue Nationale Française contre le Cancer (LNCC; Equipe labellisée 2010) and the Comités du Haut-Rhin et du Bas-Rhin. Etique $\mathrm{N}$ and Buache E were recipient of Fondation pour la Recherche Médicale and LNCC fellowship, respectively.

\section{References}

Amiry N, Kong X, Muniraj N, Kannan N, Grandison PM, Lin J et al. (2009). Trefoil factor-1 (TFF1) enhances oncogenicity of mammary carcinoma cells. Endocrinology 150: 4473-4483.

Andrew DJ, Ewald AJ. (2010). Morphogenesis of epithelial tubes: Insights into tube formation, elongation, and elaboration. Dev Biol 341: 34-55.

Bossenmeyer-Pourie C, Kannan R, Ribieras S, Wendling C, Stoll I, Thim L et al. (2002). The trefoil factor 1 participates in gastrointestinal cell differentiation by delaying G1-S phase transition and reducing apoptosis. J Cell Biol 157: 761-770.

Buron N, Guery L, Creuzot-Garcher C, Lafontaine PO, Bron A, Rio MC et al. (2008). Trefoil factor TFFl-induced protection of conjunctival cells from apoptosis at premitochondrial and postmitochondrial levels. Invest Ophthalmol Vis Sci 49: 3790-3798.

Capony F, Rougeot C, Montcourrier P, Cavailles V, Salazar G, Rochefort H. (1989). Increased secretion, altered processing, and glycosylation of pro-cathepsin D in human mammary cancer cells. Cancer Res 49: 3904-3909.

Chenard MP, Tomasetto C, Bellocq JP, Rio MC. (2004). Urinary pS2/ TFF1 levels in the management of hormonodependent breast carcinomas. Peptides 25: 737-743.

Choi EJ, Oh HM, Wee H, Choi CS, Choi SC, Kim KH et al. (2009). Eupatilin exhibits a novel anti-tumor activity through the induction of cell cycle arrest and differentiation of gastric carcinoma AGS cells. Differentiation 77: 412-423.

Corte MD, Tamargo F, Alvarez A, Rodriguez JC, Vazquez J, Sanchez R et al. (2006). Cytosolic levels of TFF1/pS2 in breast cancer: Their relationship with clinical-pathological parameters and their prognostic significance. Breast Cancer Res Treat 96: $63-72$.

Crosier M, Scott D, Wilson RG, Griffiths CD, May FE, Westley BR. (2001). High expression of the trefoil protein TFF1 in interval breast cancers. Am J Pathol 159: 215-221.

deFazio A, Chiew YE, Sini RL, Janes PW, Sutherland RL. (2000). Expression of c-erbB receptors, heregulin and oestrogen receptor in human breast cell lines. Int J Cancer 87: 487-498.

Dickins RA, Hemann MT, Zilfou JT, Simpson DR, Ibarra I, Hannon GJ et al. (2005). Probing tumor phenotypes using stable and regulated synthetic microRNA precursors. Nat Genet 37: 1289-1295.

Doll F, Pfeilschifter J, Huwiler A. (2005). The epidermal growth factor stimulates sphingosine kinase-1 expression and activity in the human mammary carcinoma cell line MCF7. Biochim Biophys Acta 1738: $72-81$.

Dunnwald LK, Rossing MA, Li CI. (2007). Hormone receptor status, tumor characteristics, and prognosis: a prospective cohort of breast cancer patients. Breast Cancer Res 9: R6.

Emami S, Le Floch N, Bruyneel E, Thim L, May F, Westley B et al. (2001). Induction of scattering and cellular invasion by trefoil peptides in src- and RhoA-transformed kidney and colonic epithelial cells. Faseb $J$ 15: 351-361.
Foekens JA, Rio MC, Seguin P, van Putten WL, Fauque J, Nap M et al. (1990). Prediction of relapse and survival in breast cancer patients by pS2 protein status. Cancer Res 50: 3832-3837.

Giese A, Bjerkvig R, Berens ME, Westphal M. (2003). Cost of migration: invasion of malignant gliomas and implications for treatment. J Clin Oncol 21: 1624-1636.

Hoffmann W. (2005). Trefoil factors TFF (trefoil factor family) peptide-triggered signals promoting mucosal restitution. Cell Mol Life Sci 62: 2932-2938.

Hoffmann W. (2007). TFF (trefoil factor family) peptides and their potential roles for differentiation processes during airway remodeling. Curr Med Chem 14: 2716-2719.

Karam SM, Tomasetto C, Rio MC. (2008). Amplification and invasiveness of epithelial progenitors during gastric carcinogenesis in trefoil factor 1 knockout mice. Cell Prolif 41: 923-935.

Katoh M. (2003). Trefoil factors and human gastric cancer (review). Int J Mol Med 12: 3-9.

Khan ZE, Wang TC, Cui G, Chi AL, Dimaline R. (2003). Transcriptional regulation of the human trefoil factor, TFF1, by gastrin. Gastroenterology 125: 510-521.

Kida N, Yoshimura T, Takahashi H, Nagao S, Nozawa Y, Furukawa $\mathrm{Y}$ et al. (1993). Estrogen-inducible pS2 protein is not the key regulatory component in the proliferation of human breast cancer cells (MCF-7). Eur J Biochem 215: 671-676.

Kjellev S. (2009). The trefoil factor family - small peptides with multiple functionalities. Cell Mol Life Sci 66: 1350-1369.

Lacroix M. (2006). Significance, detection and markers of disseminated breast cancer cells. Endocr Relat Cancer 13: 1033-1067.

Lefebvre O, Chenard MP, Masson R, Linares J, Dierich A, LeMeur M et al. (1996). Gastric mucosa abnormalities and tumorigenesis in mice lacking the pS2 trefoil protein. Science 274: 259-262.

Mackay A, Tamber N, Fenwick K, Iravani M, Grigoriadis A, Dexter T et al. (2009). A high-resolution integrated analysis of genetic and expression profiles of breast cancer cell lines. Breast Cancer Res Treat 118: 481-498.

Madsen J, Nielsen O, Tornoe I, Thim L, Holmskov U. (2007). Tissue localization of human trefoil factors 1, 2, and 3. J Histochem Cytochem 55: 505-513.

Markicevic M, Petrovic A, Kanjer K, Neskovic-Konstantinovic Z, Nikolic-Vukosavujevic D. (2008). Estrogen-regulated cut-off values of pS2 and cathepsin D expression in breast carcinomas. Adv Exp Med Biol 617: 341-348.

Masson R, Lefebvre O, Noel A, Fahime ME, Chenard MP, Wendling C et al. (1998). in vivo evidence that the stromelysin-3 metalloproteinase contributes in a paracrine manner to epithelial cell malignancy. J Cell Biol 140: 1535-1541.

Mikhitarian K, Gillanders WE, Almeida JS, Hebert Martin R, Varela JC, Metcalf JS et al. (2005). An innovative microarray strategy identities informative molecular markers for the detection of micrometastatic breast cancer. Clin Cancer Res 11: 3697-3704. 
Mira E, Lacalle RA, Buesa JM, de Buitrago GG, Jimenez-Baranda S, Gomez-Mouton C et al. (2004). Secreted MMP9 promotes angiogenesis more efficiently than constitutive active MMP9 bound to the tumor cell surface. J Cell Sci 117: 1847-1857.

Perry JK, Kannan N, Grandison PM, Mitchell MD, Lobie PE. (2008) Are trefoil factors oncogenic? Trends Endocrinol Metab 19: 74-81.

Playford RJ, Marchbank T, Goodlad RA, Chinery RA, Poulsom R, Hanby AM. (1996). Transgenic mice that overexpress the human trefoil peptide $\mathrm{pS} 2$ have an increased resistance to intestinal damage. Proc Natl Acad Sci USA 93: 2137-2142.

Poulsom R, Hanby AM, Lalani EN, Hauser F, Hoffmann W, Stamp GW. (1997). Intestinal trefoil factor (TFF 3) and pS2 (TFF 1), but not spasmolytic polypeptide (TFF 2) mRNAs are co-expressed in normal, hyperplastic, and neoplastic human breast epithelium. J Pathol 183: 30-38.

Press DJ, Pharoah P. (2010). Risk factors for breast cancer: a reanalysis of two case-control studies from 1926 and 1931 Epidemiology 21: 566-572.

Prest SJ, May FE, Westley BR. (2002). The estrogen-regulated protein, TFF1, stimulates migration of human breast cancer cells. Faseb $J$ 16: $592-594$.

Regalo G, Wright NA, Machado JC. (2005). Trefoil factors: from ulceration to neoplasia. Cell Mol Life Sci 62: 2910-2915.

Ribieras S, Tomasetto C, Rio MC. (1998). The pS2/TFF1 trefoil factor, from basic research to clinical applications. Biochim. Biophys. Acta 1378: F61-F77.

Rio MC, Bellocq JP, Daniel JY, Tomasetto C, Lathe R, Chenard MP et al. (1988). Breast cancer-associated pS2 protein: synthesis and secretion by normal stomach mucosa. Science 241: 705-708.

Rio MC, Bellocq JP, Gairard B, Rasmussen UB, Krust A, Koehl C et al. (1987). Specific expression of the $\mathrm{pS} 2$ gene in subclasses of breast cancers in comparison with expression of the estrogen and progesterone receptors and the oncogene ERBB2. Proc Natl Acad Sci USA 84: 9243-9247.

Rio MC, Chenard MP, Wolf C, Marcellin L, Tomasetto C, Lathe R et al. (1991). Induction of $\mathrm{pS} 2$ and hSP genes as markers of mucosal ulceration of the digestive tract. Gastroenterology 100: 375-379.

Rodrigues S, Rodrigue CM, Attoub S, Flejou JF, Bruyneel E, Bracke $\mathrm{M}$ et al. (2006). Induction of the adenoma-carcinoma progression and Cdc25A-B phosphatases by the trefoil factor TFF1 in human colon epithelial cells. Oncogene 25: 6628-6636.

Rodrigues S, Van Aken E, Van Bocxlaer S, Attoub S, Nguyen QD, Bruyneel E et al. (2003). Trefoil peptides as proangiogenic factors in vivo and in vitro: implication of cyclooxygenase-2 and EGF receptor signaling. Faseb $J$ 17: 7-16.

Scott DJ, Parkes AT, Ponchel F, Cummings M, Poola I, Speirs V. (2007). Changes in expression of steroid receptors, their downstream target genes and their associated co-regulators during the sequential acquisition of tamoxifen resistance in vitro. Int $J$ Oncol 31: 557-565.
Shi SQ, Cai JT, Yang JM. (2006). Expression of trefoil factors 1 and 2 in precancerous condition and gastric cancer. World J Gastroenterol 12: $3119-3122$.

Smid M, Wang Y, Klijn JG, Sieuwerts AM, Zhang Y, Atkins D et al. (2006). Genes associated with breast cancer metastatic to bone. $J$ Clin Oncol 24: 2261-2267.

Stotter A, Walker R. (2009). Tumour markers predictive of successful treatment of breast cancer with primary endocrine therapy in patients over 70 years old: a prospective study. Crit Rev Oncol Hematol 75: 249-256.

Surowiak P, Materna V, Gyorffy B, Matkowski R, Wojnar A, Maciejczyk A et al. (2006). Multivariate analysis of oestrogen receptor alpha, pS2, metallothionein and CD24 expression in invasive breast cancers. Br J Cancer 95: 339-346.

Thim L. (1997). Trefoil peptides: from structure to function. Cell Mol Life Sci 53: 888-903.

Thullberg M, Stromblad S. (2008). Anchorage-independent cytokinesis as part of oncogenic transformation? Cell Cycle 7: 984-988.

Thuwajit P, Chawengrattanachot W, Thuwajit C, Sripa B, May FE, Westley BR et al. (2007). Increased TFF1 trefoil protein expression in Opisthorchis viverrini-associated cholangiocarcinoma is important for invasive promotion. Hepatol Res 37: 295-304.

Tjensvoll K, Gilje B, Oltedal S, Shammas VF, Kvaloy JT, Heikkila R et al. (2009). A small subgroup of operable breast cancer patients with poor prognosis identified by quantitative real-time RT-PCR detection of mammaglobin A and trefoil factor $1 \mathrm{mRNA}$ expression in bone marrow. Breast Cancer Res Treat 116: 329-338.

Tomasetto C, Masson R, Linares JL, Wendling C, Lefebvre O, Chenard MP et al. (2000). pS2/TFF1 interacts directly with the VWFC cysteine-rich domains of mucins. Gastroenterology 118: 70-80.

Tomasetto C, Rio MC. (2005). Pleiotropic effects of Trefoil Factor 1 deficiency. Cell Mol Life Sci 62: 2916-2920.

Tomasetto C, Wolf C, Rio MC, Mehtali M, LeMeur M, Gerlinger P et al. (1989). Breast cancer protein PS2 synthesis in mammary gland of transgenic mice and secretion into milk. Mol Endocrinol 3: 1579-1584.

Tosco A, Monti MC, Fontanella B, Montefusco S, D'Andrea L, Ziaco B et al. (2010). Copper binds the carboxy-terminus of trefoil protein 1 (TFF1), favoring its homodimerization and motogenic activity. Cell Mol Life Sci 67: 1943-1955.

Vestergaard EM, Nexo E, Wendt A, Guthmann F. (2008). Trefoil factors in human milk. Early Hum Dev 84: 631-635.

Wilson CL, Sims AH, Howell A, Miller CJ, Clarke RB. (2006). Effects of oestrogen on gene expression in epithelium and stroma of normal human breast tissue. Endocr Relat Cancer 13: 617-628.

() This work is licensed under the Creative Commons

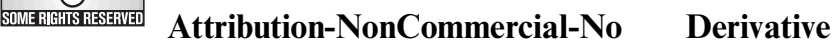
Works 3.0 Unported License. To view a copy of this license, visit http://creativecommons.org/licenses/by-nc-nd/3.0/

Supplementary Information accompanies the paper on the Oncogene website (http://www.nature.com/onc) 